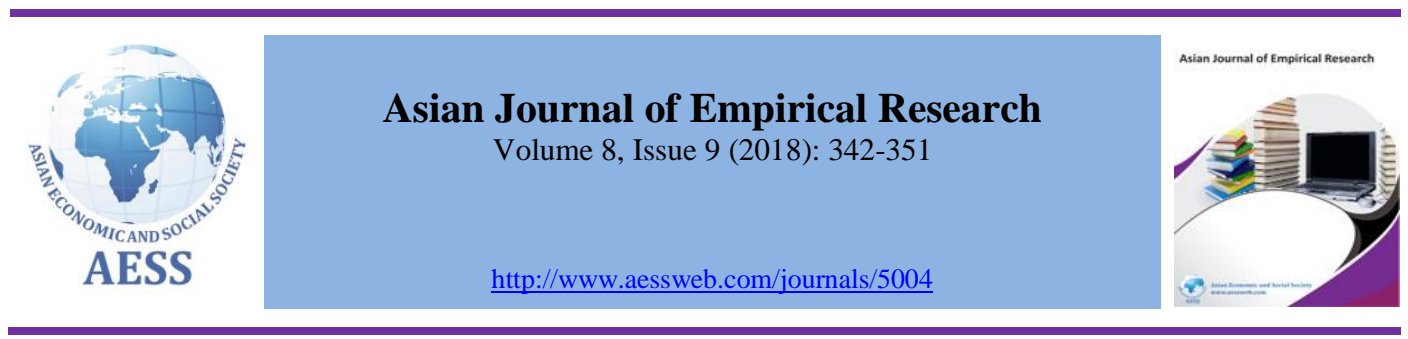

\title{
Performance on the road: examining the critical role of training effectiveness amongst the blue-collar employees in Bahrain
}

\section{(D) Umair Ahmed ${ }^{\mathrm{a}}$,Soleman Mozammel $^{\mathrm{a}}$, Habib Ahmed}

${ }^{a}$ Arab Open University, Bahrain.

${ }^{\mathrm{b}}$ Alsadiq Transport, Bahrain.

\soleman.muzammel@aou.org.bh Corresponding author

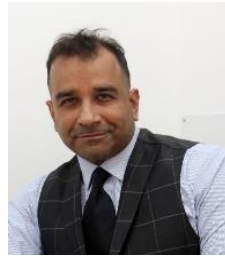

(Corresponding author)

\section{ARTICLE HISTORY:}

Received: 10-Sep-2018

Accepted: 05-Nov-2018

Online available: $21-\mathrm{Nov}-$

2018

\section{Keywords:}

Performance,

Training effectiveness,

Blue-collar,

Transportation industry,

Bahrain

\begin{tabular}{l}
\hline ABSTRACT \\
The present study attempted to investigate the role or training \\
effectiveness on the employee performance of blue-collar \\
employees working in Bahrain Transportation sector. Therein, the \\
study examined the effectiveness of five different training \\
programs offered to large vehicle drivers serving in the \\
transportation industry. A total of 135 bus drivers from Alsadiq \\
transport company Bahrain were sampled for the study to outline \\
the effectiveness of three major training programs that they were \\
offered including Customer Handling \& Passenger Safety, Health \\
$\&$ Hygiene and Guide to traffic laws and driving in Bahrain on \\
their driving performance. Structural equation modeling using \\
smart PLS was used for the present study for data analysis and \\
interpretation. The study found a significant relationship impact of \\
two programs on their driving performance of the respondents. \\
The study forwards theoretical and practical implications and \\
scope for further studies.
\end{tabular}

\section{Contribution/ Originality}

This study is one of the few empirical studies conducted in the transportation sector of Bahrain. The study has attempted to underline the significant role and contribution of training effectiveness on performance of blue-collar employees.

DOI: 10.18488/journal.1007/2018.8.9/1007.9.342.351

ISSN (P): 2306-983X, ISSN (E): 2224-4425

How to cite: Umair Ahmed, Soleman Mozammel and Habib Ahmed (2018). Performance on the road: examining the critical role of training effectiveness amongst the blue-collar employees in Bahrain. Asian Journal of Empirical Research, 8(9), 342-351.

(C) 2018 Asian Economic and Social Society. All rights reserved 


\section{INTRODUCTION}

Organizations today are spending millions to help boost employee outcomes and behaviors at work. There has been a phenomenal increase in the focus of companies towards initiatives through which employees could be aided to boost their outcomes (Ahmed et al., 2018). Let it be public or private sector, this trend is picking up momentum as the corporate world has realized its criticality in the current competitive market. Borate et al. (2014) have defined training as a methodical learning of skills to improve performance. Training has become a highly important HR components these days whereby, many organizations are actively spending and allocating hefty budget to boost business outcomes (Ford, 2014). Employee training has become essential for many reasons since all employees need it to get appropriate skills for their jobs. It generally encourages the employee to get ideas about the job procedures. Additionally, it helps them to adjust in with any given situation and/or condition hence enabling them to improve their performance. Notably, it is important for organizations to evaluate and/or examine as to what extent a certain training program is important and effective so that more objective training programs can be launched. This assessment of the effectiveness of each training program is also significant in outlining how and to what extent the business is evidently concerned about its training programs and how they continuously influence employee behaviors and outcomes (Kirkpatrick and Kirkpatrick, 2014).

Performance is the ultimate expectation of every business entity, let it be individual or organizational (Ahmed et al., 2018; Umrani et al., 2016; Ahmed et al., 2017). Organizations are spending millions globally to come up with ways and/or strategies through which performance can be enhanced. Notably, employee training has turned to be one major component in this regard (Ahmed et al., 2017; Bartel, 1994).

According to (Bohlander and Snell, 2010) organizations are increasingly spending more and more money every year on training to have the capacity to content in the local and the global market. Governments also consider training and developing people as the first step towards solving the unemployment problem in their nations. Training refers to an act of gaining new skills and knowledge to perform a given task(s) whereas effectiveness of a training program denotes to the responsiveness of a training programs towards enabling individuals to achieve the desired objectives (Werner and DeSimone, 2009). Training is described as "change agent", which asserts that its primary purpose is to cause a change in employee knowledge, skills performance and/or behaviour. Training professionals are considered to be change leaders in organizations. They are important and potentially strategic to help directing change through programs and through the behaviours they model. The major role of training professionals is to figure out how to change the skills, behaviours and routines of individuals to meet or even exceed business expectations and performance requirements. They have to constantly observe and assess what needs to be developed in order to enhance their performance. In principle organizations invest in people to help them enrich their work behaviors, maximize performance achieve organizational objectives (Rothwell et al., 2003).

Generally, training professionals, as change leaders, motivate the workforce to embrace change, creative direction for the change efforts, help the organization's workforce adapt to change, and ensures that interventions are continuously monitored and guided in ways consistent with stockholders' desired results. They should work through a team of change (Rothwell et al., 2003). Borate et al. (2014) have defined the training as a methodical learning of skills to improve performance. All employees need it to get appropriate skills for those jobs. It generally encourages the employee to get ideas about the job procedure and help them to adjust in with any condition. The training results in growth of employees which leads to improve the organization wide performance. Training is also explained as a systematic process to provide essential information to employees, necessary to boost their performance. It is very important for any organization to know if the employees implementing what they learn during the training events. Evaluation for training normally helps to explore the value of training. It is processing to evaluate the outcomes and determines the importance of training and how it effect on the employees and organizational goals. 
Every training program should be assessed to ensure that they are in line with the organizational expectations. Notable scholars have underlined the significance of training on employee behaviors and outcomes (Ahmed et al., 2015; Ahmed et al., 2016; Ahmed et al., 2017).

\section{KIRKPATRICK MODEL OF TRAINING}

Kirkpatrick' model has Four stages (reaction, learning, behavior and results) for training evaluation. It is the most model used training evaluation. It's written to find a far-reaching diagram for actualizing the model in a way that really expands the organization outcomes. Utilizing these creative ideas, standards, methods, and contextual investigations, you can better train the employees, enhance the way of organizations, and, at last, enable the organization to meet its most critical objectives. The first stage is about employees discover the importance of training and applicable to their employment. The second stage is about employees obtain the expected information, abilities, demeanor, certainty and responsibility in view of their support in the training. The third stage is about employees apply what they realized amid training when they are back at work. Fourth stage is about focused on results happen because of the training (Kirkpatrick and Kirkpatrick, 2016).

Training Programs generally refer to events designed for training employees in specific skills. This program provides the employees with Knowledge and new skills. Accordingly, training effectiveness refers to objectivity of the training towards enabling attendees to attain required performance and outcomes (Werner and DeSimone, 2009). Many organizations are committed to providing training for their employees, but a few of them are actually concerned about evaluating training effectiveness. In fact, training specialists at big organizations are fully aware that the ultimate goal of training is to improve the employee performance which eventually results in improving the overall organizational performance and productivity. Therefore, when evaluating training effectiveness, training professionals must go beyond the element of just conducting the training programs. Henceforth, following the assertions of Kirkpatrick model, the present study attempted to test the impact of training programs on the learning, reaction and changes in work behavior and performance of the employees in the transportation business to outline their effectiveness respectively.

\subsection{Training programs at al-Sadiq transport}

Companies usually offer a wide variety of training programs, keeping in view their customer base, nature of business, market and industry requirements. Pertaining to the transportation business generally, health, safety, customer handling and traffic law-based training programs are the most common and popular. Bearing these in mind, Al-Sadiq transport also offer similar programs that match the industry needs and business requirements. These programs are health and hygiene, customer handling and passenger safety and traffic laws and driving in Bahrain. Management at AlSadiq transport believes that these training programs are critical for their employees to give excellent driving performance.

Generally, companies offer health and hygiene programs to help the organizations, staffs, and others improve and develop work environment health and hygiene programs, prepare plans of action to prevent accidents or occupational diseases, and to conduct investigations as some of the many ways to meet and achieve good health and safety practices in the working environment. (HAS, 2018).

Accordingly, programs related to customer handling and passenger safety are provided in servicebased organizations on a higher note whereby, participants are taken to gain an in-sight into customer handling and how service businesses can ensure safety of passenger. The element of passenger safety goes critical for business like Sadiq transport which deals with providing transportation services to its customers. Similarly, guide to traffic laws and driving in Bahrain is another important training program provided by transportation businesses. Sadiq transport believes the program to be of high importance in ensuring that the drivers are well aware of the traffic laws and hence drive appropriately. Since the present is based on case study approach, it attempted to test 
to what extent these three training programs are becoming effective in boosting the driving performance of the drivers in Al-Sadiq Transport.

\subsection{Hypothesis testing}

Keeping in view the three major training programs offered to the blue-collar employees in the chosen company, the present study tested the following hypotheses to outline which ones are perceived to be more effective by the respondents in connection to their driving performance.

H1: Customer handling and passenger safety training programs will be positively perceived by the blue-collar employees to the extent that it will have a positive influence on their driving performance

$\mathrm{H} 2$ : Guide to traffic laws and driving in Bahrain training program will be positively perceived by the blue-collar employees to the extent that it will have a positive influence on their driving performance.

H3: Health and Hygiene will be positive perceived by the blue-collar employees to the extent that it will have a positive influence on their driving performance.

\subsection{Measurements}

Three prominent mandatory training programs provided to all the driving staff were assessed to examine how they were influencing their driving performance. Effectiveness of customer handling \& passenger safety was assessed through 3-item scale that enquired respondents to outline the importance of the trainings, its effectiveness and their understandability of the content. Similarly, Health \& Hygiene was also examined through 3 -items enquiring the importance of the training program, its effectiveness and understandability of the content. Likewise, effectiveness regarding guide to traffic laws and driving in Bahrain was also examined through 3 -item scale examining the similar prospects. Lastly, driving performance was examined through 4 -item scale.

\subsection{Sampling and data collection}

All the full time employed drivers of Al-Sadiq transport were sampled for the present study which totaled to 135 during the month of February 2018 through using self-administered questionnaire. The respondents were clearly informed pertaining the confidentiality of the personal details of the respondents so that they could respond to the questionnaire with full objectivity.

Keeping in view the lack of understanding and literacy issue, the drivers were invited in batches of 15 whereby, they were given details explanation on the aim of the study and explanation on the each of the statement in the question so that they could respond effectively. The study resulted with 126 valid questionnaires that were taken further for data analysis.

\subsection{Data analysis}

Structural equation modeling (Wold, 1985) using Smart PLS 2.0 was employed in the present study (Ringle et al., 2005). The SEM procedure performs the data analysis in two stages and they are:

- Assessment of measurement model

- Assessment of structural model (Hair et al., 2014).

\subsection{Measurement model}

Measurement model caters to the examination of individual items loadings, AVE scores and alpha coefficients which are known as he psychometric properties of the conceptualized framework. In connection to the assessment of individual item loadings, all the items resulted with loadings higher than the recommended threshold of 0.50 (Chin, 1998; Hair et al., 2014). Therein, items of customer handling and passenger safety ranged between 0.748 to 0.907 ; health and hygiene ranged between 0.854 to 0.900 . Accordingly, individual items of guide to traffic laws and driving in Bahrain scored between 0.854 to 0.869 wherein, individual item loadings for driving performance ranged between 
0.871 to 0.895 . Accordingly, the present study also examined the average variance extracted to ensure the convergent validity whereas per Chin (1998), the AVE scores should be greater than 0.50 . Table 1 shows that all the constructs resulted in higher AVE scores thus confirming convergent validity. Parallel to this, the study also assessed the composite reliability scores to affirm internal consistency reliability of the constructs. As per Bagozzi and Yi (1988), the CR scores should be greater than or equal to 0.70 . Table 1 and Figure 1 highlights that all the constructs resulted in values higher than the recommended threshold thus, confirming sufficient internal consistency.

Table 1: AVE, Loadings and composite reliability

\begin{tabular}{lcccc}
\hline Construct & Loadings & AVE & $\begin{array}{l}\text { Composite } \\
\text { Reliability }\end{array}$ & $\mathbf{R}^{\mathbf{2}}$ \\
\hline $\begin{array}{l}\text { Customer Handling \& } \\
\text { Passenger Safety }\end{array}$ & & 0.740 & 0.822 & \\
CHPS1 & 0.907 & & \\
CHPS2 & 0.914 & & 0.905 & 0.236 \\
CHPS3 & 0.748 & & \\
Driving Performance & & 0.780 & \\
DP1 & 0.871 & & \\
DP2 & 0.896 & & \\
DP3 & 0.895 & & \\
DP4 & 0.869 & & \\
Guide to Traffic Laws \& & & 0.766 & \\
Driving in Bahrain & & & \\
GTLDB1 & 0.8698 & & \\
GTLDB2 & 0.9005 & & \\
GTLDB3 & 0.8547 & 0.637 & \\
Health \& Safety & 0.8681 & & \\
HH1 & 0.8434 & & \\
HH2 & 0.669365 & & \\
HH3 & &
\end{tabular}

Following to this the study also examined discriminant validity for each of the construct. As per Chin (1998) the discriminant validity should be assessed through taking the square root of AVE scores in a cross table. Therein, the square root values should be greater than the reflective loadings of other constructs. Table 2 highlights scores in this regard whereby, all the square root of each construct`s AVE score has ranged higher in comparison with the other reflective loadings thus, confirming adequate discriminant validity.

Table 2: Discriminant validity

\begin{tabular}{lllll}
\hline Construct & & & & \\
\hline CHPS & 0.8603 & & & \\
DP & 0.4211 & 0.8831 & 0.8752 & \\
GTLDB & 0.5720 & 0.4329 & 0.7537 & 0.7985 \\
HH & 0.5071 & 0.3903 & 0.757 \\
\hline
\end{tabular}




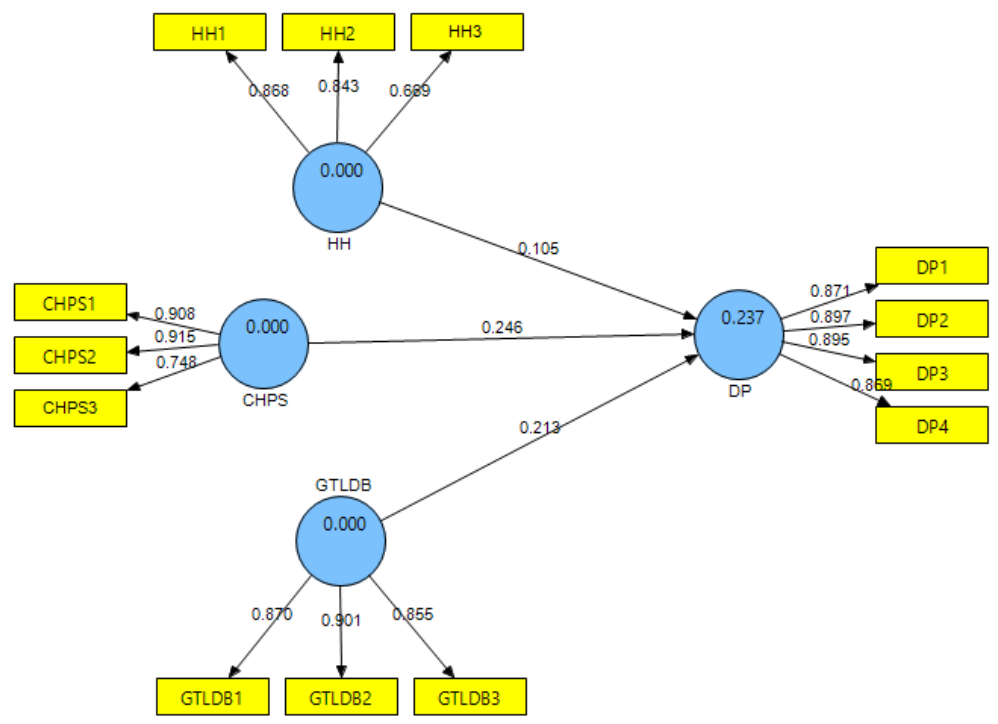

Figure 1: Measurement model

\subsection{Structural model}

Upon the successful confirmation of measurement model, the present study tested the structural model which caters to the examination of significance of the path coefficients between the hypothesized relationships. Bootstrapping procedures were applied in this regard, whereby, 5000 bootstrap sample was employed to test these relationships. Table 2 highlights that the respondents perceived positive about customer handling and passenger safety practices training program and hence enhancing their driving performance. This result thus has landed support for hypothesis 1 . Accordingly, the study has found significantly positive results regarding guide to traffic laws and driving in Bahrain training program and driving performance relationship. In other words, the drivers viewed the training program to be higher effective thus resulting in boosting their driving performance and waving support for hypothesis 2 . However, the present study did not find any support for health and hygiene training program and its impact on the driving performance of the drivers. In other words, the respondents did not perceive health and hygiene to be effective enough to facilitate them towards harnessing their driving performance thus rejecting hypothesis 3 . Table 3 and figure 2 provides further detail in this regard.

Table 3: Structural model results

\begin{tabular}{lcccc}
\hline Relationship & Sample Mean & Std Error & T-Value & Decision \\
\hline CHPS -> DP & 0.2460 & 0.0665 & 3.694 & Supported \\
GTLDB -> DP & 0.2132 & 0.0830 & 2.567 & Supported \\
HH -> DP & 0.1048 & 0.0833 & 1.258 & Not Supported \\
\hline
\end{tabular}




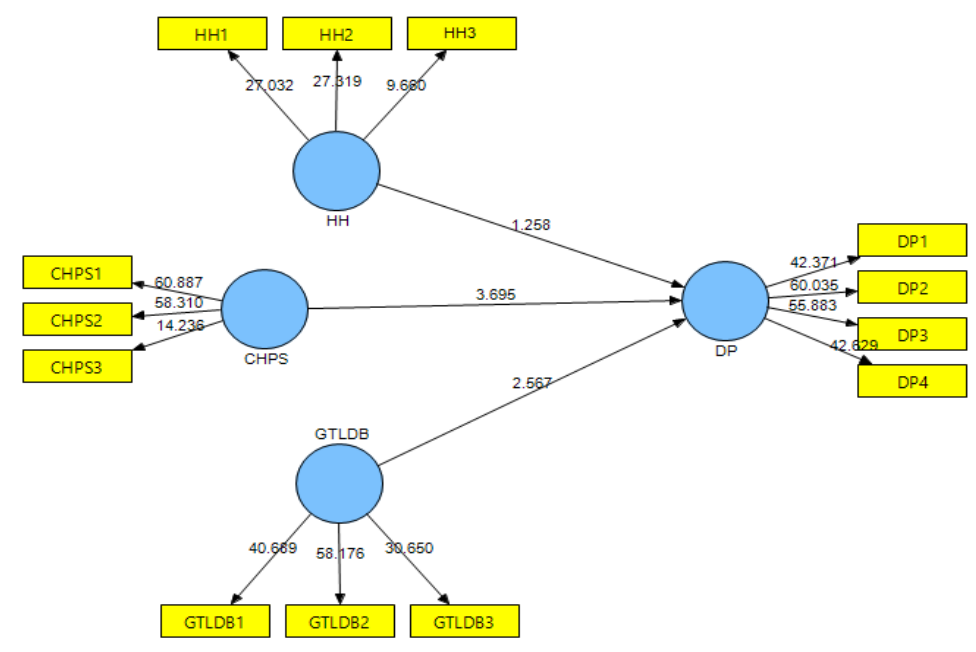

Figure 2: Structural model

\section{DISCUSSION}

The present study attempted to examine the effectiveness of training programs in the context of enhancing evident performance of the drivers in a transportation business in Bahrain. In specific, the study examined three major training programs offered to the blue-collar employees (drivers) of a large transportation company in the country to see how effective they are perceived in relation to boosting their driving performance. The study found significant results on the hypothesized relationship between customer handling and passenger safety training program and driving performance. The findings suggest that the drivers viewed customer handling the study also and passenger safety training to be an important and effective one for their work outcomes and behaviors in particular thus, boosting their driving performance. This hence highlights that the drivers found this training program to be highly effective in harnessing their on-road performance. Similarly, the respondents also forwarded significant results for training program related to guide to traffic laws and driving in Bahrain in connection to driving performance. The study found that there is a significant relationship between these two elements henceforth confirming the need, importance and vitality of this training program towards boosting the driving performance of the blue-collar employees in the transportation business. on a higher note, the health and hygiene training program resulted to be insignificant in relation with driving performance in the present study. This could possibly be due to the fact that health and hygiene training program relates to the individual physical health and wellbeing and therefore is not concerned with the driving performance directly.

\subsection{Implications for theory and practice}

Overall, the findings of the present study have outlined that there is a significant relationship between training and performance in general. In particular, the results have also underlined a significant impact of individual training program effectiveness with the performance of employees as the present study found two training programs perceived as effective in boosting their driving performance. This hence goes in consonance with the meta-analysis results of Arthur et al. (2003) and Noe (1986). The results hence forwards implications for top management and people in-charge of organizing and conducting training program pertaining to employees` perceptions regarding each training program offered. The findings have underlined that regardless of the need and importance of each training program, it is important to understand that not every individual will potentially view all offered training programs to be equally vital. 
Additionally, with regards to performance prospects, it is important for businesses to understand the relevance of each of the training program against the behavior and/or outcome it is assessed since not every training program can possibly influence every employee outcomes(s). In particular, the findings have forwarded implications for managers and top management in Al-Sadiq transport pertaining to the three major training programs offered to the drivers in the company. The findings have underlined that in relation to the driving performance two of the training programs were found to be effective which thus implies less relevance and vitality of the third program. Based on the findings, the company may launch a training program more relevant to their performance.

\subsection{Recommendations}

The present study attempted to outline the effectiveness of training programs offered to blue-collar employees (drivers) at Alsadiq Transport Company in Bahrain. The findings have outlined that these employees viewed customer handling and passenger safety training program to be very effective for managing improving their performance. This finding hence suggests boosting this program and enriching it further to enhance the drivers` performance on the roads. Customer handling is a major component of service industry and employees working in the transportation business particularly in the school business handling young pupils unquestionably require sufficient training in this regard. Accordingly, the study also found significant results pertaining to the influence of traffic laws and driving performance management training program. The finding suggests that the employees at Alsadiq see the program fruitful and beneficial for them to improve their performance on the road. The company may offer also relevant training programs to help them better understand traffic laws and driving practices in Bahrain. Lastly, in connection to health and hygiene, the study found insignificant results which could be possibly because of the limited direct link of the training program with their driving performance. In order to improve the link between health and hygiene and drivers ' performance, the company may possibly enrich the training program through including information as to how good health and hygiene can help them to stay active and productive hence boosting their performance. The company also attempts to review the course to see if there is anything lacking in it.

\subsection{Limitations and Scope for further Studies}

Besides notable empirical contributions, the present study also has some important limitations. Firstly, the present study was conducted through cross sectional means whereby, the study only focused on the effectiveness of training programs in one particular company. Henceforth, scholars in this domain may attempt to investigate training effectiveness across a wider work sector. Accordingly, with the case study approach, the present study only catered to a small sample size therefore, a bigger sample is advised for future studies to help understand the effectiveness of training programs on employee performance. Likewise, longitudinal study is also recommended keeping in view the cross sectional design of the study to have generalizable results. In parallel, future scholar may also consider investigating the effectiveness of training programs across different organizational set ups and/or industries to unearth how it connects with individual performance. Pertaining to the performance, future studies may also attempt to look into exploring the impact of training on group performance.

\section{CONCLUSION}

The present study has found a significant relationship between effectiveness of the training program(s) and their connection with the performance prospects of employees in a business set up. In relation to the transportation business, the present study found that the blue-collar employees (drivers) viewed training programs related to customer handling \& passenger safety and traffic laws as highly effective thus, enhancing their driving performance. 
Funding: This study received no specific financial support.

Competing Interests: The authors declared that they have no conflict of interests.

Contributors/Acknowledgement: All authors participated equally in designing and estimation of current research.

Views and opinions expressed in this study are the views and opinions of the authors, Asian Journal of Empirical Research shall not be responsible or answerable for any loss, damage or liability etc. caused in relation to/arising out of the use of the content.

\section{References}

Ahmed, U., Phulpoto, W., Umrani, W. A., \& Abbas, S. I. (2015). Diving deep in employee training to understand employee engagement. Business and Economics Journal, 7(1). 199-202. view at Google scholar / view at publisher

Ahmed, U., Majid, A. H. A., \& Zin, M. L. M. (2016). HR Moderating HR: critical link between developmental HR practices and work engagement in a moderated model. Management Review: An International Journal, 11(2), 4-22. view at Google scholar

Ahmed, U., Isa, N. M., Majid, A. H. A., Zin, M. L. M., \& Amin, B. M. (2017). Towards understanding work engagement: can HR really buffer HR? Test of a moderated model. International Journal of Economic Research, 14(20), 1-18. view at Google scholar

Ahmed, U., Khalid, N., Ammar, A., \& Shah, M. H. (2017). Assessing moderation of employee engagement on the relationship between work discretion, job clarity and business performance in the banking sector of Pakistan. Asian Economic and Financial Review, 7(12), 1197-1210. view at Google scholar / view at publisher

Ahmed, U., Shah, M. H., Siddiqui, B. A., Shah, S. A., Dahri, A. S., \& Qureshi, M. A. (2017). Troubling job demands at work: Examining the deleterious impact of workload and emotional demands on work engagement. International Journal of Academic Research in Business and Social Sciences, 7(6), 96-106. view at Google scholar / view at publisher

Ahmed, U., Shah, S. A., Qureshi, M. A., Shah, M. H., \& Khuwaja, F. M. (2018). Nurturing innovation performance through corporate entrepreneurship: the moderation of employee engagement. Studies in Business and Economics, 13(2), 20-30. view at Google scholar / view at publisher

Arthur Jr, W., Bennett Jr, W., Edens, P. S., \& Bell, S. T. (2003). Effectiveness of training in organizations: A meta-analysis of design and evaluation features. Journal of Applied psychology, 88(2), 234-245. view at Google scholar / view at publisher

Bagozzi, R. P., \& Yi, Y. (1988). On the evaluation of structural equation models. Journal of the Academy of Marketing Science, 16(1), 74-94. view at Google scholar

Bartel, A. P. (1994). Productivity gains from the implementation of employee training programs. Industrial Relations: A Journal of Economy and Society, 33(4), 411-425. view at Google scholar / view at publisher

Bohlander, G. W., \& Snell, S. (2010). Managing human resources. USA: Cengage Learning. view at Google scholar

Borate, N. S., Gopalkrishna, D., \& Borate, S. L. (2014). A case study approach for evaluation of Employee Training. International conference on global business, economics, finance and social sciences. view at Google scholar / view at publisher

Chin, W. W. (1998). The partial least squares approach to structural equation modeling. Modern Methods for Business Research, 295(2), 295-336. view at Google scholar

Ford, J. K. (Ed.). (2014). Improving training effectiveness in work organizations. Psychology Press. view at Google scholar / view at publisher

Hair, J. F., Hult, G. T. M., Ringle, C. M., Sarstedt, M. (2014). A primer on partial least squares structural equation modeling, (PLSSEM). Thousand Oaks, CA: Sage. view at Google scholar I view at publisher

HAS. (2018). Health and safety workplaces. Retrieved from: http://hsa.ie/eng/ [Accessed 18 January 2018]

Kirkpatrick, D., \& Kirkpatrick, J. (2014). Evaluating training programs: the four levels. USA: Berrett-Koehler Publishers. view at Google scholar 
Kirkpatrick, J. D., \& Kirkpatrick, W. K. (2016). Kirkpatrick's four levels of training evaluation. USA: Association for Talent Development. view at Google scholar

Noe, R. A. (1986). Trainees' attributes and attitudes: Neglected influences on training effectiveness. Academy of Management Review, 11(4), 736-749. view at Google scholar / view at publisher

Ringle, C. M., Wende, S., \& Will, A. (2005). Smart PLS 2.0 M3, University of Hamburg. '^'eds. '): Book Smart Pls, 2, M3. view at Google scholar

Rothwell, W. J., Lindholm, J. E., \& Wallick, W. G. (2003). What CEOs expect from corporate training: building workplace learning and performance. USA: American Management Association. view at Google scholar

Umrani, W. A., Mahmood, R., \& Ahmed, U. (2016). Unveiling the direct effect of corporate entrepreneurship's dimensions on the business performance: a case of big five banks in Pakistan. Studies in Business and Economics, 11(1), 181-195. view at Google scholar / view at publisher

Werner, J. M., \& DeSimone, R. L. (2009). Human Resource Development. UK: South-Western Cengage Learning. view at Google scholar

Wold, H. (1985). Partial least squares. In S. Kotz \& N. L. Johnson (Eds.), Encyclopedia of statistical sciences (Vol. 6, pp. 581-591). New York, NY: Wiley. view at Google scholar 